\title{
Proteção ao meio ambiente e às gerações futuras: desdobramentos e reflexões bioéticas
}

\author{
Protection of the environment and future generations: bioethical \\ developments and reflections
}

Isis Laynne de Oliveira Machado', Volnei Garrafa'

DOI: $10.1590 / 0103-1104202012419$

RESUMO A dicotomia entre a promessa de que o desenvolvimento tecnológico representa a solução para os problemas humanos e a crescente certeza quanto à finitude de recursos naturais criam uma gama de incertezas quanto às expectativas para o futuro, ainda mais diante dos crescentes problemas ambientais que vêm surgindo. $O$ trabalho objetivou adentrar ao princípio da proteção, avaliando como este pode interagir com o princípio da precaução, contribuindo para a compreensão da complexidade da temática ambiental e a necessidade de mudanças no comportamento humano com relação ao futuro planetário. O estudo utiliza como método uma revisão bibliográfica de autores que atualmente tratam do assunto, envolvendo as constantes transformações do mundo, mudanças climáticas e necessidade de um desenvolvimento sustentável, problemas interligados e de cunho global. A partir da bioética normativa, serão expostos os artigos 16 e 17 da Declaração Universal sobre Bioética e Direitos Humanos, discutindo e entrelaçando os conceitos de proteção e de precaução. Propõe-se uma reflexão quanto ao modo de compreender as mudanças ocorridas no mundo, com base em uma bioética comprometida com a conscientização humana, de que é necessário adotar ações conjuntas, visando à preservação do planeta, para resguardar a saúde e a própria sobrevivência das gerações futuras.

PALAVRAS-CHAVE Bioética. Proteção. Precaução. Meio ambiente. Saúde.

\begin{abstract}
The dichotomy between the promise that technological development represents the solution to human problems and the growing certainty about the finitude of natural resources creates a range of uncertainties regarding expectations for the future, even more so in view of the growing environmental problems that are emerging. The work aimed to enter the principle of protection, evaluating how it can interact with the precautionary principle, contributing to the understanding of the complexity of the environmental theme and the need for changes in human behavior in relation to the planetary future. The study uses as a method a bibliographic review of authors who currently deal with the subject, involving the constant transformations of the world, climate changes and the need for sustainable development, interconnected problems and of a global nature. Based on normative bioethics, articles 16 and 17 of the Universal Declaration on Bioethics and Human Rights will be exposed, discussing and interweaving the concepts of protection and precaution. A reflection is proposed as to how to understand the changes that have occurred in the world, based on a bioethics committed to human awareness, that it is necessary to adopt joint actions, aiming at the preservation of the planet, in order to safeguard the health and survival of future generations.
\end{abstract}

1 Universidade de Brasília (UnB), Programa de PósGraduação em Bioética, Cátedra Unesco de Bioética - Brasília (DF), Brasil.

isis_laynne@hotmail.com 


\section{Introdução}

A bioética, como ramo do conhecimento e da ética aplicada, é campo para discussões dos mais variados aspectos da vida, o que envolve a temática inerente ao futuro dos seres humanos, os impactos de suas ações ao meio ambiente e o modo como vivem.

No âmago de tal preocupação, em 1971, Potter ${ }^{1}$ utilizou o termo bioética para descrever a necessidade de uma ética voltada a solucionar dilemas éticos inerentes aos avanços tecnológicos e o futuro dos seres vivos. $\mathrm{O}$ autor publicou o livro intitulado 'Bioética: Ponte para o futuro', posicionando-se no sentido de que a bioética deveria representar, tal como uma ponte, o diálogo e a intersecção entre os avanços da tecnologia e seu impacto para a vida humana e do planeta. Sua ideia era apresentar a bioética como um ramo do conhecimento em que valores éticos pudessem ser aplicados a temas envolvendo meio ambiente, saúde, biologia, ciência etc.

Apesar do termo 'bioética' ter obtido nova conotação, a partir dos estudos produzidos por Beauchamp e Childress ${ }^{2}$, com o passar dos anos, constatou-se que a vertente da bioética por eles defendida, pautada em quatro princípios (autonomia, beneficência, não maleficência e justiça) voltados à esfera biomédica, não seria suficiente para sanar problemas éticos de âmbito global. Atualmente, faz-se necessária uma ética aplicada a problemas que envolvam a vida humana, incluindo variados aspectos e atuando de forma politizada e crítica ${ }^{3}$ diante dos dilemas humanos.

O mundo encontra-se em constantes transformações, em grande parte advindas de ações antrópicas, que têm causado grande impacto no ecossistema. Tais mudanças precisam ser mais bem compreendidas a fim de evitar a ocorrência de maiores efeitos negativos e, possivelmente, catastróficos.

A preocupação com uma ética que abranja a vida humana em seus mais amplos aspectos e o futuro do planeta é proposição de ordem mundial. Tanto é que, no ano de
2005, foi promulgada a Declaração Universal sobre Bioética e Direitos Humanos da Unesco (DUBDH), que tem como propósito nortear os países signatários quanto a dilemas relacionados com a medicina e as tecnologias associadas; com o respeito pelos direitos humanos, especialmente no que tange à necessidade de proteção de determinados grupos 4 ; bem como quanto à "Proteção das Gerações Futuras" e à "Proteção do Meio Ambiente, da Biosfera e da Biodiversidade", presentes nos seus artigos 16 e $17^{5}$.

Nesse sentido, é importante ressaltar que o desenvolvimento científico trouxe consigo promessa de solucionar os problemas vivenciados pelos seres humanos, deixando de lado, inicialmente, a preocupação com a finitude dos recursos naturais e o impacto para o meio ambiente. Hoje, as mudanças climáticas representam alguns dos problemas causados pelas ações humanas, sendo objeto recorrente para os estudos em bioética.

É indispensável registrar já no início do presente estudo que a Declaração de Bioética da Unesco avançou na sua proposta com relação ao histórico conceito de saúde 4 referido ao completo estado de bem-estar físico, mental e social, criado na segunda metade do século $\mathrm{XX}$, passando a incorporar novos referenciais à sua fundamentação teórica ${ }^{3}$, entre os quais se encontram os artigos 16 e 17. O artigo 14 da DUBDH, por sua vez - que trata especificamente da "Responsabilidade Social e Saúde"5(8) -, inclui temas considerados até algumas décadas como distantes do campo da saúde pública e coletiva: além da "redução da pobreza e do analfabetismo"5(8) e da "eliminação da marginalização e da exclusão de indivíduos [...]"5(8), inclui o "acesso a nutrição adequada e água de boa qualidade" ${ }^{(8)} \mathrm{e}$ "a melhoria das condições de vida e do meio ambiente"5(8). Nesse sentido, e em consonância com essa territorialização epistemológica proposta pela DUBDH ao conceito de saúde, ao se referir à proteção ambiental e à responsabilidade para com as gerações futuras, o presente artigo está considerando e incluindo em todo o transcurso do texto - naturalmente - a temática sanitária. 
Tomando como referência a linha de ideias acima exposta, este trabalho tem por objeto propor reflexões bioéticas quanto ao princípio da proteção, avaliando as possíveis conexões com o princípio da precaução, de modo a entender a complexidade que envolve a temática ambiental e a necessidade de alterar o modo de vida humano, a fim de preservar a vida planetária.

Este estudo tem cunho teórico, com base na revisão bibliográfica acerca do assunto. Inicialmente, será realizada breve apresentação do cenário atual envolvendo as constantes transformações do mundo, mudanças climáticas e necessidade de um desenvolvimento sustentável, por serem problemas interligados e de cunho global. Após, serão expostos os artigos $16 \mathrm{e} 17$ da DUBDH, a fim de realizar melhor discussão quanto ao conceito de proteção, entrelaçando-o ao conceito de precaução. Em seguida, será exposta reflexão quanto ao modo de compreender as mudanças ocorridas no mundo, procurando demonstrar a importância da bioética como ferramenta teórico-metodológica comprometida com a necessidade de adoção de ações conjuntas no intuito de alterar o modo de vida atual por meio da conscientização humana, visando à preservação do planeta e resguardando o direito de existência às gerações futuras.

\section{O desenvolvimento humano e as preocupações com $o$ futuro do planeta}

Tratar de perspectivas do futuro é assunto recorrente, já que a sobrevivência humana está atrelada também a procedimentos de melhoramento da vida e à existência de recursos naturais no planeta. Assim, falar em proteção de gerações futuras implica também tratar de responsabilidades quanto à manutenção de vidas que estão por vir.

Segundo Pfeiffer, Murguía e Gandhi', a modernidade separou a ordem 'natural' da 'humana' como se o homem não pertencesse ao natural, criando o pensamento utópico de que a natureza é um instrumento para suprir as necessidades humanas e que, portanto, deveria ser submetida às leis da razão. Durante os séculos XVIII e XIX, não havia dúvida de que os seres humanos - por meio do domínio da ciência, técnica, arte e filosofia - poderiam controlar os fenômenos naturais que pudessem significar um entrave para alcançar o progresso. A ciência, a técnica, o progresso e a racionalidade eram os componentes que garantiriam um futuro mais livre e mais humano, razão pela qual o avanço nos conhecimentos práticos e teóricos eram essenciais para que o ser humano não fosse submetido às leis naturais, devendo a natureza ser meio para alcançar a felicidade humana.

No entanto, a promessa da ciência moderna acabou se convertendo em ameaça contra a natureza e contra o próprio ser humano que pretendeu exercer seu domínio ${ }^{6}$. A permanente busca por novidades e o uso desenfreado dos recursos naturais geraram um alerta quanto à diminuição e limitação dos recursos naturais do planeta.

$\mathrm{O}$ avanço industrial e tecnológico trouxe consigo diversos benefícios para a humanidade, mas promoveu também a ideia de que os recursos naturais poderiam ser utilizados sem limites e que as consequências poderiam ser remediadas por novas tecnologias, o que não tem se mostrado factível, pelo contrário, tem criado diversas incertezas quanto ao futuro. As mudanças climáticas, advindas da ação humana na natureza, também têm sido objeto de especial preocupação já que o desenvolvimento desenfreado acabou por alterar a vida e o habitat de diversos seres vivos. Tais fatos ensejam a adaptação do modo de vida humana, voltada ao aspecto sustentável.

Para melhor compreender o atual cenário planetário, faz-se necessário tecer breves argumentações a respeito das consequências que as ações humanas têm causado ao planeta, para, posteriormente, adentrar às reflexões bioéticas acerca do princípio da proteção e seus desdobramentos. 


\section{O mundo em metamorfose}

O desenvolvimento industrial significou um marco para a mudança do modo de vida humano, que ganhou perspectiva de uma vida voltada para a produção e consumo de bens, sem preocupar-se com as consequências de tal desenvolvimento para com a finitude dos recursos naturais. A incessante busca pelo melhoramento da vida humana e a crença de que a tecnologia é capaz de responder às necessidades humanas permitiram interferências significativas na natureza, tais como a produção de alimentos geneticamente modificados, o uso de pesticidas, a clonagem de animais, a alteração genética de insetos com vistas a reduzir proliferação de doenças etc., o que originou um desequilíbrio no ecossistema.

Contudo, o que pouco se discute são as consequências de tais intervenções e alterações na natureza. Segundo Junges ${ }^{7}$, a

[...] máxima expressão das consequências do binômio tecnologias e vida sobre o meio, é a crise ecológica com seus efeitos sobre as mudanças climáticas e sobre a sustentabilidade ambiental do planeta7(3).

Tal crise é um dos principais desafios a serem enfrentados pela humanidade nas próximas décadas, para assegurar a preservação do conjunto de seres vivos e da própria humanidade.

Há alguns anos, cresceu a preocupação com os impactos globais acarretados pelos longos períodos de extrativismo natural, pela poluição gerada pelas indústrias e pela quantidade de lixo despejada no mundo. No entanto, alguns "ainda acham que não é necessário mudar os rumos, porque a sociedade sempre encontrará caminhos tecnológicos para obviar a crise"8(15). A dicotomia entre a promessa que o desenvolvimento tecnológico representa a solução para os problemas humanos e a crescente certeza quanto à finitude de recursos naturais cria uma gama de incertezas em relação às expectativas para o futuro, ainda mais diante dos crescentes problemas ambientais que vêm surgindo.

Segundo Beck ${ }^{9}$, vivemos em uma sociedade de risco, ou seja, em mundo governado pelas leis da probabilidade, em que se fabricam cada vez mais incertezas, especialmente no que diz respeito ao rápido desenvolvimento tecnológico, aplicado ao uso genético, nanotecnologia e ciência da informática, desencadeando uma série de consequências imprevisíveis, incomunicáveis e incontroláveis, capazes de ameaçar a vida na Terra. Para o autor:

[...] não são as mudanças climáticas, os desastres ecológicos, ameaças de terrorismo internacional, o mal da vaca louca etc. que criam a originalidade da sociedade de risco, mas a crescente percepção de que vivemos em um mundo interconectado que está se descontrolando $9(7)$.

Por isso, afirma que a organização política e social tem se tornado historicamente obsoleta, apesar de ainda permanecer governando nosso pensamento e modo de agir. Tal fato mostra a necessidade de que sejam desenvolvidos meios para melhor compreensão do mundo contemporâneo.

Beck $^{\mathbf{1 0}}$ faz uma distinção entre 'mudanças' e 'metamorfose', ressaltando que a primeira traz uma concepção de futuro característico da modernidade, qual seja, a de transformação permanente, sendo que os conceitos básicos e as certezas que os sustentam são constantes, especialmente em seus aspectos sociológicos, destacando o estudo de rotinas humanas como chave para a sociologia. Já a segunda desestabiliza os conceitos da sociedade moderna e muda o foco de 'estar no mundo' e 'ver o mundo', para eventos e processos que não são intencionais, que geralmente passam despercebidos e vão além dos domínios da democracia política, como efeitos colaterais da modernização técnica e de economia.

Em síntese, a metamorfose significa essa mudança que ultrapassa as constantes 
antropológicas anteriores, acerca da compreensão do mundo, para atingir um grau tão elevado de mudanças, a ponto de alcançar o que era impensável anteriormente. $\mathrm{O}$ autor aqui mencionado cita como exemplos a queda do muro de Berlim e o ataque terrorista de 11 de setembro, situações até então inconcebíveis às quais temos assistido de nossa sala de estar, transmitidas pelos meios de comunicação em massa. Ou seja, para ele, a mudança representa uma constante, enquanto a metamorfose representa um patamar mais elevado e inesperado de alteração do mundo que conhecemos. Vive-se então em um mundo que não apenas está mudando, mas está se transformando de maneira muito mais radical, isto é, em metamorfose.

\section{Mudanças climáticas}

As mudanças climáticas representam outro problema de escala mundial, já que respondem a uma cadeia de produção iniciada pelo desenvolvimento industrial, que desencadeou o atual alto nível de poluição, ocasionando aquecimento global; que, por sua vez, tem causado o aumento da temperatura média do planeta, elevando o nível do mar, o que acarreta o desaparecimento de ilhas, alagamento de cidades litorâneas e até mesmo a alteração do ciclo de vida de diversas espécies da natureza. Tais fatos são alarmantes para o futuro no planeta, já que a vida depende do equilíbrio de todo o ecossistema.

A resposta do meio ambiente às ações humanas pode ser compreendida, na concepção da metamorfose, como possibilidade de alterações catastróficas ambientais. Nesse prisma, Beck ${ }^{10}$ afirma que a ênfase em descobrir soluções para evitar ou diminuir as mudanças climáticas cega os sujeitos para o fato de que esta não deixa de ser agente central da metamorfose, que já alterou o modo de vida humano no mundo. Exemplo disso é o fato de que o aumento do nível do mar tem criado paisagens de desigualdade, desenhando novos mapas com modificação das linhas fronteiriças entre os Estados.

Garvey"1, por sua vez, ressalta que apesar de os estudos éticos estarem mais preocupados com questões inerentes à clonagem, eutanásia ou modificações genéticas, por exemplo, a reflexão acerca das mudanças climáticas se mostra indispensável, porquanto o mundo está mudando, sendo necessário adotar ações em resposta a tais mudanças. $\mathrm{O}$ autor ressalta ainda que a ciência é capaz de nos dar maior controle sobre os fatos, mas não é capaz de dar respostas eficazes para alterar o atual cenário mundial.

As mutações climáticas, advindas de buracos na camada de ozônio, aumento da temperatura planetária, degelo de calotas polares e desertificação de regiões, representam problemas ambientais que ameaçam o ecossistema da Terra ${ }^{12}$, mas também influenciam nos campos político e econômico, já que a modificação geográfica e de fronteiras representa também alteração de territórios.

Sob outra perspectiva, a busca por respostas rápidas e pontuais aos problemas existentes introduz uma lógica de imediatismo exacerbado, que impede de pensar em medidas em longo prazo, como é o caso da necessidade da adoção de um modo de vida que resulte em menos impactos negativos ao planeta.

Assim, é fundamental a existência de estudos e reflexões éticas acerca das ações humanas e a forma como a ciência se desenvolve, avaliando suas consequências para a vida das pessoas, para a sua saúde e para o próprio planeta. Como se observa, o mundo contemporâneo tem atravessado uma série de mudanças capazes de comprometer até mesmo a continuidade de sua existência e dos seres que nele habitam.

\section{Desenvolvimento sustentável}

Nascimento ${ }^{13}$, ao tratar do desenvolvimento sustentável como uma das soluções para a crise ambiental vivida no mundo, apresenta uma crítica quanto à adoção de meios mais eficazes 
para preservação dos recursos naturais, entre eles, as mudanças culturais, defendendo a necessidade de adoção de outros valores e comportamentos, tais como: a) que noção de felicidade se desloque do 'consumir' para o 'usufruir'; b) transferência da moda, visando à durabilidade do produto; e c) pressões para a valorização e melhora de transportes coletivos.

Para ele, o desenvolvimento sustentável deve ser compreendido em sua complexidade, abordando cautelosamente os aspectos tecnológicos e sua promessa de superação dos limites dos recursos naturais, agregado à necessidade de uma mudança radical na forma como se produz e consome bens e serviços. Manifesta-se ainda reticente quanto à adoção de políticas para decrescimento populacional, defendendo que a solução está na mudança de postura na forma como se lida com os recursos naturais e o pouco receio de que estes efetivamente acabem.

O autor aduz que o século XXI traz consigo três signos, quais sejam: a contradição entre os indícios de crescimento da crise ambiental e a fragilidade das medidas adotadas; [a incerteza] quanto ao futuro da humanidade no acirramento das crises econômica e ambiental; [e a esperança] de que transformações sociais ocorram, mudando - para meIhor - o padrão civilizatório a que estamos

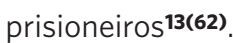

Como se nota, tratar da temática ambiental quanto ao futuro remete a uma série de problemas, que partem desde o avanço industrial, tecnológico e suas promessas para o futuro, incluindo a reflexão acerca da ação antrópica na natureza e a forma como se deixa de observar o modo de vida sustentável. Tais temáticas, apesar de distintas, conectam-se na medida em que trazem a necessidade de reflexão quanto ao mundo para o qual se está caminhando.

No próximo tópico, será abordada a temática da necessidade de proteção das gerações futuras, tomando por base a DUBDH e algumas concepções bioéticas acerca do tema.

\section{A temática ambiental na Declaração sobre Bioética e Direitos Humanos da Unesco}

No século XXI, como exposto na Introdução do artigo, a bioética passou a adotar viés de 'macrobioética' ou 'ética global', por se ocupar de temas relevantes no planeta, como é o caso da globalização e necessidade de proteção ao meio ambiente e das gerações futuras. Tais fatos ampliaram sua gestão para temas inerentes à saúde e à vida das pessoas e comunidades, que deixam de ser individuais ou sociais para serem globais e atemporais. A relação entre o ser humano, sua saúde, vida e o ambiente tornou-se então um problema ético, causado pelo aceleramento do desenvolvimento científico e econômico e pelas alterações ocasionadas nos sistemas ecológicos globais ${ }^{\mathbf{1 4}}$.

Ciente de que o futuro da vida planetária depende também da preservação dos recursos naturais, a temática foi incorporada à DUBDH ${ }^{5}$. Entre os 15 princípios norteadores para a tomada de decisões éticas no que tange à vida humana em seus mais variados aspectos, encontram-se aqueles que dizem respeito à 'Proteção das Gerações Futuras' e à 'Proteção do Meio Ambiente, da Biosfera e da Biodiversidade'. Tais dispositivos prescrevem que:

Artigo 16 - Proteção das Gerações Futuras O impacto das ciências da vida sobre gerações futuras, incluindo sobre sua constituição genética, deve ser devidamente considerado.

Artigo 17 - Proteção do Meio Ambiente, da Biosfera e da Biodiversidade

Devida atenção deve ser dada à inter-relação de seres humanos com outras formas de vida, à importância do acesso e utilização adequada de recursos biológicos e genéticos, ao respeito pelo conhecimento tradicional e ao papel dos seres humanos na proteção do meio ambiente, da biosfera e da biodiversidade ${ }^{5(7-8)}$. 
Como se percebe, a preocupação com o futuro do planeta e dos seres que nele habitam foi um dos temas de destaque na DUBDH, demonstrando a importância do assunto para os estudos bioéticos que, indubitavelmente, têm ampliado seu campo de abrangência para além de aspectos biomédicos, abrangendo discussões éticas de cunho ambiental ${ }^{15}$.

É importante salientar que o termo 'proteção' remete à ideia de cuidado; defesa; afastamento do perigo; habitat; e preservação ${ }^{16}$. Segundo Kottow ${ }^{17}$, a tradição do conceito de proteção advém do nascimento do Estadonação e da elaboração filosófica-política do contrato social, sendo, inicialmente, o Estado responsável pela elaboração de políticas que visem à proteção de seus cidadãos. Contudo, esclarece, o Estado não é capaz de garantir efetivamente a proteção de pessoas e grupos mais vulneráveis, sendo necessária uma ética voltada ao estudo de como aplicar a proteção em casos concretos.

Afirma ainda que a ética da proteção pode ser compreendida de dois modos: em sua forma stricto sensu, buscando a igualdade social, empoderamento dos excluídos e o cuidado aos necessitados; e em sua forma lato sensu, em uma perspectiva de ética geral, que aspira a novas formas de cosmopolitismo lastreado em uma ética de hospitalidade incondicional.

Schramm ${ }^{18}$, ao tratar do tema, afirma a necessidade de proteger não somente os sujeitos morais, mas o próprio “'mundo da vida' (Lebenswelt) frente às possíveis consequências daninhas dos atos de agentes morais que podem prejudicar os pacientes morais"18(1534). Assim, há que se preocupar com "práticas predatórias que afetam o planeta como um todo e a humanidade como espécie"19(12), cujos efeitos podem ser visivelmente notados pelas mudanças climáticas, poluição generalizada, redução da biodiversidade e escassez de água.

Tais noções, trazidas para o campo da preservação do ambiente e salvaguarda das gerações futuras, remetem a compreender a proteção como forma de cautela e uso responsável de tecnologias, a fim de que as gerações futuras ainda possam dispor de meios para viver. Assim, a ética da proteção, atrelada a aspectos bioéticos, deve estar voltada não apenas para aspectos individuais, inerentes aos seres humanos e seus direitos, mas à vida humana como espécie, de modo a preservar a sobrevivência dos seres que habitam o planeta.

Anteriormente, Jonas ${ }^{20}$ já havia desenvolvido um estudo acerca do princípio da responsabilidade, afirmando que, por conta da intervenção técnica do homem, a natureza encontra-se em estado de extrema vulnerabilidade, que hodiernamente se faz reconhecível por meio dos danos causados e suas consequências. Para ele, a natureza é responsabilidade humana, a qual exige reflexões éticas acerca das consequências que a ação dos homens tem causado ao planeta. Isso implica buscar o bem não apenas das vidas humanas, mas das extra-humanas também.

Jonas ${ }^{20}$ afirma ainda que o 'dever' é uma classe da responsabilidade, na medida em que se deve adotar medidas que propiciem a existência das gerações futuras, ou seja, para com a existência humana, ainda que não se deixem descendentes diretos. Ainda segundo o autor, a ausência de um comportamento ativo e responsável, no intuito de preservar e diminuir os danos futuros, implica um comportamento irresponsável, isto é, o 'não fazer' também é danoso. Assim, as interferências humanas e suas tecnologias devem ser utilizadas prudentemente, de modo a não colocar em risco a sobrevivência da humanidade.

É importante ressaltar que trazer para o escopo da DUBDH artigos inerentes à preocupação quanto à proteção das gerações futuras remonta à bioética pensada por Potter, como ponte de ligação entre ciências humanas e biológicas ${ }^{17}$.

O melhoramento de técnicas, ao mesmo tempo que gera a sensação de que a tecnologia poderá sanar os problemas ambientais e garantir a sobrevivência do planeta e da humanidade por muitos anos, gera também a incerteza de que as tecnologias produzidas serão capazes de fato fazê-lo, já que seu uso 
inconsequente acarretou ao atual cenário. Por isso, é imperativo que, nas discussões bioéticas, seja também abordada a importância de proteção das gerações futuras, que pressupõe - além da temática da saúde e suas implicações mais diretas - a proteção da biosfera, do meio ambiente e da biodiversidade.

A noção de proteção deve ser entrelaçada com outros princípios para ser mais bem compreendida e aplicada, visto que o atual contexto requer não apenas a redução de danos causados ao meio ambiente, mas melhor gestão dos riscos inerentes à atividade humana.

\section{Precaução como atributo para proteção de gerações futuras}

A proteção deve ocorrer de forma ativa, por meio da adoção de práticas que visem diminuir os efeitos negativos da ação humana e os impactos que esta pode acarretar para a vida planetária. O princípio da proteção pode ser atrelado ao princípio da precaução, como forma de nortear o gerenciamento dos riscos advindos das atividades humanas no planeta.

Segundo Garrafa et al. ${ }^{21}$, a precaução pode ser compreendida como

[...] a adoção de medidas protetoras relativas a possíveis danos ou riscos que poderiam ser produzidos por determinados produtos ou tecnologias. [...]. Nessa linha de ideias, seu propósito precípuo é a proteção da humanidade e do meio ambiente contra possíveis ameaças dos atos humanos 21(131).

A precaução mostra-se importante ferramenta, principalmente quando se sabe da existência dos riscos de determinada ação, mas estes não são totalmente conhecidos ou previsíveis.

Como forma de proteger o meio ambiente, os Estados devem observar o princípio da precaução, de modo que, na iminência de ameaças de danos sérios ou irreversíveis, devem ser adotadas medidas para prevenir a degradação ambiental. Com isso, o princípio da precaução tem por finalidade "a implementação de melhores decisões possíveis em estados de incerteza e de conhecimento indisponível, inacessível ou mesmo inexistente"22(127).

Por sua vez, Hammerschmidt ${ }^{23}$ diferencia os princípios da prevenção e da precaução, visto que o primeiro refere-se à gestão de riscos e danos já conhecidos e mensuráveis, cujas consequências movem-se dentro das certezas das ciências; o segundo, por sua vez, enfrenta os riscos gerados pela incerteza dos saberes científicos, que são imensuráveis e imprevisíveis. Ou seja, enquanto o primeiro refere-se ao perigo concreto, o segundo refere-se ao perigo abstrato, mas iminente.

A ideia de precaução revela a necessidade de uma ética da decisão aplicada a um contexto de incertezas, causada pelo paradigma da segurança existencial - pautada no progresso e na tecnologia -, que acabou dando lugar ao medo - gerado pela ideia de que se vive constantemente exposto ao risco. A importância do princípio da precaução está justamente no pressuposto de que é necessário gerir os riscos ambientais, adotando-se uma atitude de "antecipação preventiva que se revela a longo prazo como menos onerosa para a sociedade e o ambiente e mais justa e solidária com as gerações futuras"23(113).

O princípio da precaução responde às incertezas não apenas quanto à relação de causalidade entre o ato e suas consequências, mas também quanto à realidade e medida do risco e do dano. Contudo, a aplicação de tal princípio não se mostra simples, visto que exige a gestão do exercício ativo da dúvida, ou seja, a uma ampliação da incerteza, do que pode ou não ocorrer. Saliente-se que a "incerteza não exonera de responsabilidade; ao contrário, ela reforça a criar um dever de prudência"23(109).

O princípio da precaução, agregado ao de proteção, centra-se na ideia de que medidas para a proteção ambiental devem ser adotadas de forma imediata, sendo que a incerteza ou 
ausência de certeza científica absoluta quanto aos riscos e danos não deve ser utilizada como desculpa para postergar ações, mas para adotá-las o quanto antes.

Nesse sentido, o olhar crítico e reflexivo da bioética auxilia a reconhecer e a incentivar a adoção de medidas práticas de precaução, para efetivar o princípio da proteção às gerações futuras, as quais estão atreladas aos riscos trazidos pelo desenvolvimento científico e pelo modo de vida das pessoas, que, em sua maioria, está adstrito à lógica de produção para consumo, ao invés de redução racional de consumo para preservação de recursos naturais.

O princípio da precaução impele à utilização inversa das tecnologias produzidas, para que deixem de satisfazer exclusivamente à lógica do consumo e sirvam para reduzir os níveis de poluição, evitar extinção de espécies e o crescimento do desequilíbrio ambiental, bem como incentivar ações de conscientização social. Segundo Porto e Garrafa ${ }^{24}$, faz-se necessário que as pessoas deixem de viver a lógica consumista (sem qualquer noção de responsabilidade) e passem a adotar uma lógica mais cidadã e de comunhão consensual para preservação do planeta, de modo a abandonar o individualismo exacerbado, para passar a reconhecer e dignificar o outro, agindo coletivamente para o bem comum.

\section{O papel da bioética no reconhecimento da complexidade da temática ambiental e da necessidade de alteração do comportamento humano}

$\mathrm{O}$ avanço industrial e tecnológico desenfreado é causa das mudanças climáticas, juntamente com o modo de vida capitalista, atualmente voltado ao consumo descontrolado. No entanto, a estagnação industrial, a partir de agora, não significaria, necessariamente, uma melhoria para a preservação dos recursos naturais. Por isso, há que se ter uma mudança ética quanto ao modo, finalidade e produção de tecnologias e os impactos que essas poderão acarretar ao mundo.

Morin ${ }^{25}$ afirma que o grande mal do atual sistema de conhecimento reside no fato de que os saberes foram tão compartimentados, a ponto de não mais haver uma interconexão entre eles, o que dificulta o oferecimento de respostas a questões difíceis para a humanidade. $\mathrm{O}$ autor denomina de 'pensamento complexo' aquele que une conhecimentos separados, sendo que seu maior desafio é unir os problemas segmentados ou fragmentados hoje existentes, a fim de buscar soluções articuladas. Para compreender a complexidade do ser humano e, consequentemente, do mundo, na temática ambiental, é importante que não haja sua redução a um único aspecto. Para o autor, um pensamento mutilado leva a decisões ilusórias e erradas.

Segundo Morin ${ }^{25}$,

A complexidade parece ser negativa ou regressiva já que é a reintrodução da incerteza num conhecimento que havia partido triunfalmente à conquista da certeza absoluta. É preciso enterrar esse absoluto. Porém, 0 aspecto positivo, o aspecto progressivo que a resposta ao desafio da complexidade pode ter, é o ponto de partida para um pensamento multidimensional25(188)

A forma de sistematização atual, em que a divisão de setores como consumo, saúde, lazer desenvolve sua própria forma de organização e cria insumos para se adequar aos desejos e necessidades humanas, acaba por reforçar a ausência de comunicação entre as mais diversas áreas existentes no mundo, reforçando ainda mais as consequências advindas de ações isoladas de tais setores.

Com isso, a partir da compreensão de que a proteção das gerações futuras deve ser realizada para compreender a complexidade do mundo e os diversos fatores (econômico, cultural, religioso etc.) que conduziram 
ao modo de vida hoje existente, mostra-se importante para a aplicação do princípio da proteção, atrelado ao da precaução, na busca pela gestão dos riscos.

Uma das formas de enfrentar os problemas ambientais globais é por meio do

[...] compromisso comum com ideais e princípios éticos como justiça, precaução, equidade e cooperação, destacando-se a sensibilização com o sofrimento alheio e o compartilhamento de um mesmo 'destino histórico planetário'14(406).

A adoção de um modelo de sustentabilidade dos sistemas sociais teria por objeto formar pessoas cada vez mais reflexivas e solidárias, transformando sujeitos de meros consumidores a cidadãos, preocupados com os seres vivos atuais e com as futuras gerações ${ }^{\mathbf{1 4}}$.

Por isso, há que se pensar meios éticos para administrar o desenvolvimento tecnológico a fim de reduzir seus impactos negativos sobre o mundo, tarefa central para a bioética.

Assim, é necessário maior reflexão acerca dos modos de vida que podem ser desenvolvidos de maneira sustentável, adotando-se meios públicos, tais como criação de leis ou diretrizes com o fim de conscientização quanto à necessidade de mudar o modo de vida atual, para um modo sustentável, em que a forma de utilização dos recursos não seja realizada de modo individualista, mas para o bem comum, buscando meios de manter o equilíbrio e tentar recuperar recursos danificados pela ação humana.

Enfrentar temas como metamorfose do planeta, mudanças climáticas e necessidade de um desenvolvimento sustentável passa pela compreensão de que os indivíduos estão inseridos em um mundo com uma rede de relacionamentos complexos. A interação global entre as mais diferentes espécies e a noção de interdependência dessas ${ }^{7}$, para a manutenção da vida planetária, necessita da compreensão quanto à complexidade da temática ambiental e os impactos que os atos praticados pela espécie humana têm causado em todo o globo.

A bioética tem papel relevante na concepção de tais reflexões ${ }^{7}$, na medida em que traz em seu escopo normativo aspectos de proteção e cuidado que devem ser aplicados à prática humana em busca do desenvolvimento tecnológico sustentável. Melhor dizendo, ela funciona efetivamente como uma ponte ética aplicada entre o desenvolvimento da ciência e a preservação do meio ambiente, biosfera e biodiversidade, já que toda a vida planetária se encontra entrelaçada e interdependente.

\section{Considerações finais}

A ideia de que o desenvolvimento tecnológico é capaz de gerar melhor qualidade de saúde e de vida tem sido comprovada ao longo dos anos. Contudo, a concepção de que a tecnologia e o conhecimento humano são capazes de também solucionar os problemas ambientais enfrentados no globo terrestre tem sido cada vez mais falaciosa, na medida em que a natureza e seus fenômenos não podem ser dominados ou controlados pela vontade humana.

Dessa forma, enxergar de modo crítico esse entrelaçamento de informações, produções, consumo, formas de poder e entender que tudo faz parte de uma rede vital já inicia à compreensão da complexidade do mundo em que se vive. Gera também a noção de que é fundamental adotar um olhar de responsabilidade e proteção em relação aos avanços tecnológicos e às mudanças enfrentadas no mundo não somente em escopo imediatista de proteger a saúde das pessoas no momento presente, mas, especialmente, no sentido da preservação futura da própria vida planetária.

A proteção das gerações futuras deve então estar atrelada à ideia de precaução ante os riscos iminentes das práticas humanas, não para viver uma sociedade do medo, mas uma sociedade consciente de que é preciso reformular o modo de vida, a fim de romper com a lógica de desenvolvimento industrial e tecnológico a qualquer custo, que, utilizando 
indiscriminadamente os recursos naturais, acaba por degradar o meio ambiente, causando mudanças na biosfera que podem ser catastróficas. Com isso, em resposta a tal gestão de riscos, a concepção de desenvolvimento sustentável devidamente balizada deve ser implementada pelos Estados, a partir de campanhas de conscientização acerca da mudança de comportamento e legislações rigorosas e efetivas executadas. Faz-se necessário utilizar as ferramentas disponibilizadas pelo avanço tecnológico não mais para destruição e exploração da natureza, mas para a preservação desta.

Apesar da sensação de impotência causada pela noção de complexidade do mundo e as relações entre os seres que o habitam, é necessário adotar uma postura contrária ao antropocentrismo e mais voltada à responsabilidade da humanidade para consigo mesma e com os demais seres e o ambiente. Para enfrentar o desafio da complexidade do todo, é preciso adotar medidas que iniciem uma efetiva conscientização acerca da necessidade de alteração do modo de vida atual, para que, a partir de ações individuais, o coletivo possa estar afeto a praticar ações de menor consumo e maior preservação planetária, garantindo, às gerações futuras, o direito de existência.

\section{Colaboradores}

Machado ILO (0000-0003-0051-9307)* contribuiu para a concepção, planejamento, elaboração do rascunho e elaboração da versão final do manuscrito. Garrafa V (0000-00024656-2485)* contribuiu para revisão crítica do conteúdo e elaboração da versão final do manuscrito.

\section{Referências}

1. Potter VR. Bioética: ponte para o futuro. Tradução de Diego Carlos Zanella, São Paulo: Edições Loyola; 2016

2. Beauchamp TL, Childress JF. Princípios de ética biomédica. Edições Loyola; 2002.

3. Garrafa V. Inclusão social no contexto político da bioética. Bioética. 2005; 1(2):122-32.
4. Barbosa SN. A participação brasileira na construção da Declaração Universal sobre Bioética e Direitos Humanos da Unesco. Bioética. 2006; 2(4):423-442.

5. Organização das Nações Unidas para a Educação, a Ciência e a Cultura. Declaração Universal sobre Bioética e Direitos Humanos (DUBDH). Brasília, DF: Universidade de Brasília, 2005. [acesso em 2018 out 5]. Disponível em: https://goo.gl/hFyLt4.
*Orcid (Open Researcher and Contributor ID). 
6. Pfeiffer ML, Murguía D, Gandhi I. Ecología y sustentabilidad: el fantasma de la pobreza. Medicina y Humanidades. Santiago de Chile. 2010; (1):41-51.

7. Junges JR. Principios ecológico-éticos de la sostenibilidad socio ambiental: el caso de la Economía y de la Agricultura. Revista Iberoamericana de Bioética. 2016 [acesso em 2020 jan 20]; (1):1-13. Disponível em: https://revistas.comillas.edu/index.php/bioetica-revista-iberoamericana/article/view/6767.

8. Junges JR. Bioética e Meio Ambiente num Contexto de América Latina Bioethics and Environment in a Context of Latin America. Revista Redbioética/ Unesco. 2014; 5,1(9):13-19.

9. Beck U. Incertezas fabricadas. IHU. 2006 [acesso em 2018 nov 12]; (4):5-13. Disponível em: http://www. ihuonline.unisinos.br/media/pdf/IHUOnlineEdicaol81.pdf.

10. Beck U. The metamorphosis of the world: How climate change is transforming our concept of the world. John Wiley \& Sons. 2016; 5(3):177-179.

11. Garvey J. The EPZ Ethics of Climate Change: Right and Wrong in a Warming World. London: Bloomsbury; 2008 .

12. Junges JR. Ética ecológica: antropocentrismo ou biocentrismo?. Perspectiva Teológica. 2001; 33(89):33.

13. Nascimento EP. Trajetória da sustentabilidade: do ambiental ao social, do social ao econômico. Estudos avançados. 2012; 26(74):51-64.

14. Fischer ML, Cunha T, Renk V, et al. Da ética ambiental à bioética ambiental: antecedentes, trajetórias e perspectivas. Hist. ciênc. saúde-Manguinhos. 2017; 24(2):391-409.

15. Garrafa V. Da bioética de princípios a uma bioética interventiva. Bioética. 2005; 13(1):125-134

16. Houaiss. Dicionário. Dicionário online de português. 2016. [acesso em 2018 nov 15]. Disponível em: https:// www.dicio.com.br/proteger/.
17. Kottow M. Bioética de protección. In: Tealdi JC, organizador. Diccionario latinoamericano de bioética. Bogotá: UNESCO, Red Latinoamericana y del Caribe de Bioética, Universidad Nacional de Colombia; 2008. p. 165-167

18. Schramm FR. A bioética de proteção: uma ferramenta para a avaliação das práticas sanitárias?. Ciênc. Saúde Colet. 2017; 22(5):1531-1538.

19. Schramm FR. Bioética da proteção: ferramenta válida para enfrentar problemas morais na era da globalização. Bioética. 2009; 16(1):11-23.

20. Hans J. El principio de responsabilidad: ensayo de una ética para la civilización tecnológica. Barcelona: Herder; 1995.

21. Garrafa V, Amorim K, Garcia T, et al. Bioética e vigilância sanitária. Rev. direito sanit. 2017; 18(1):121-139.

22. Liedke MS, Schiocchet T. O direito e a proteção das gerações futuras na sociedade de risco global. Veredas Direito. 2012; 9(17):109-31.

23. Hammerschmidt D. O risco na sociedade contemporânea e o princípio da precaução no direito ambiental. Seqüência. 2002; 23(45):97-122.

24. Porto D, Garrafa V. Bioética de intervenção: considerações sobre a economia de mercado. Bioética. 2009 [acesso em 2020 jan 20]; 13(1). Disponível em: http:// revistabioetica.cfm.org.br/index.php/revista_bioetica/article/view/96.

25. Morin E. Ciência com Consciência. 8. ed. Rio de Janeiro: Bertrand Brasil; 2005.

\footnotetext{
Recebido em 15/03/2019

Aprovado em 10/01/2020

Conflito de interesses: inexistente

Suporte financeiro: Programa de Pós-Graduação em Bioética

da Universidade de Brasília, com apoio da Coordenação de

Aperfeiçoamento de Pessoal de Nível Superior (Capes)/Ministério da Educação (MEC)
} 